\title{
Implementasi Algoritma Genetika Dalam Penjadwalan Jeda Iklan Pada Stasiun Radio 99.1 Most FM
}

\author{
Mutiah*, Efori Buulolo, Natalia Silalahi \\ Program Studi Teknik Informatika, Universitas Budi Darma, Medan, Indonesia \\ Email: ${ }^{1}$ mutiahtambunan@gmail.com
}

\begin{abstract}
Abstrak
Pemutaran iklan pada sebuah stasiun radio komersial dilakukan setiap hari mulai dari hari minggu sampai Sabtu. Pada stasiun radio komersial, pada umumnya pembuatan jadwal iklan masih secara manual yang mana hal ini berakibat kelambatan penyajian jadwal iklan mingguan. Waktu pemutaran terdiri dari dua jenis yaitu prime time dan regular time. Penjadwalan Iklan Radio yang akan dibahas pada penelitian ini adalah pemutaran iklan yang dilakukan pada jadwal siar radio yaitu antara jam 5 pagi sampai jam 24 malam di mana dengan aturan setiap 15 menit disediakan 3 slot pemutaran iklan dengan durasi per iklan maksimumnya adalah 1 menit. Jadi jika waktu siar radio per hari adalah 19 jam, maka jumlah maksimum iklan per hari yang dapat ditayangkan adalah 76 iklan. Aturan lainnya adalah diberlakukannya prime time yaitu jam-jam dimana masyarakat umum (pendengar) mempunyai peluang terbesar mendengarkan radio yaitu antara jam 6:00-10:00 pagi dan jam 16:00-20:00 malam. Jumlah pemutaran iklan yang sama pada satu hari dibatasi untuk prime time yaitu 5 kali, sedangkan untuk regular time 8 kali. Proses penjadwalan radio dilakukan menggunakan algoritma genetika yang terdiri dari proses-proses inisialisasi kromosom, seleksi, crossover serta mutasi. Kromosom pada penelitian ini terdiri dari 3 gen, yang mana setiap kromosom akan dievaluasi berdasarkan nilai fitnesnya yang dihitung berdasarkan jumlah pelanggaran aturan yang terjadi pada setiap kromosom dalam suatu individu. Dimana aturan 1 adalah jumlah pemutaran per iklan tidak boleh lebih dari 5 kali dalam satu hari dan aturan 2 adalah tidak boleh ada dua atau lebih penjadwalan iklan yang ditayangkan pada hari dan waktu yang sama. Setelah itu diperoleh nilai fitnes masing-masing kromosom, maka dilakukan seleksi, crossover dan mutasi. Dari penelitian ini dihasilkan jadwal iklan yang optimal dengan menjadwalkan keseluruhan data iklan, hari dan waktu pemutaran iklan
\end{abstract}

Kata Kunci: Penjadwalan; Jeda; Iklan; Algoritma Genetika

\section{Abstract}

The screening of advertisements on a commercial radio station is done every day from Sunday to Saturday. In commercial radio stations, in general, making ad schedules is still manually which results in delays in the presentation of the weekly ad schedule. Playback time consists of two types, namely prime time and regular time. Radio Ad Scheduling that will be discussed in this study is the ad screening that is carried out on the radio broadcast schedule, which is between 5 am to 24 pm in which with the rules every 15 minutes are provided 3 ad playback slots with a maximum duration of 1 minute per ad. So if the radio broadcast time per day is 19 hours, then the maximum number of ads per day that can be displayed is 76 ads. Another rule is the implementation of prime time, the hours at which the general public (listeners) have the greatest opportunity to listen to the radio, which is between 6:00 and 10:00 in the morning and 16:00-20: 00 at night. The number of screenings of the same advertisement on one day is limited to prime time which is 5 times, while for regular time is 8 times. The radio scheduling process is carried out using genetic algorithms consisting of chromosome initialization, selection, crossover and mutation processes. The chromosomes in this study consist of 3 genes, each chromosome will be evaluated based on its fitness value which is calculated based on the number of violations of rules that occur on each chromosome in an individual. Where rule 1 is the number of plays per advertisement that cannot be more than 5 times in a day and rule 2 is that there cannot be two or more ad scheduling shows on the same day and time. After that the fitness value of each chromosome is obtained, then the selection, crossover and mutation are carried out. From this research an optimal ad schedule is produced by scheduling overall ad data, day and time of ad playback

Keywords: Scheduling; Pause; Advertising; Genetic Algorithms

\section{PENDAHULUAN}

Radio merupakan salah satu media massa dan media penyiaran yang bersifat konvensional namun masih banyak digunakan oleh semua lapisan masyarakat. Tidak hanya sekedar sebagai media untuk mencari hiburan, radio juga sebagai media penyedia informasi dan komunikasi. Layanan informasi yang disampaikan kepada masyarakat salah satunya adalah berupa iklan. Iklan merupakan salah satu cara yang digunakan dalam melakukan promosi baik berupa barang maupun jasa. Iklan adalah informasi yang isinya membujuk khalayak banyak atau orang banyak supaya tertarik kepada barang atau jasa yang ditawarkan. Iklan radio memiliki karakteristik yang khas yaitu hanya dapat didengar melalui audio (suara) yang merupakan perpaduan dari kata-kata (voice), music dan sound effect.

Penayangan dan penjadwalan jeda iklan pada radio Most FM memerlukan manajemen yang baik yang mencakup pemesanan siar (broadcast), jam siar serta sesuai dengan durasi dan frekuensi iklan. Manajemen yang kurang baik akan berakibat kerugian pada radio Most FM. Jadwal iklan yang baik akan memberikan dampak baik berupa pendapatan pada stasiun radio Most FM. Masalah sering terkendala dalam lamanya penyajian jadwal iklan mingguan sehingga berkurang pemasukan dari jasa penayangan iklan. Iklan dalam radio Most FM sering terkendala dalam penayangan iklan karena harus membagi jenis-jenis iklan dan menentukan waktu penayangan sesuai slot-slot yang ada, dan juga pembagian jam tayang prime time dan reguler time. Rumitnya cara pembuatan jadwal penayangan iklan radio membuat penjadwalan iklan di Most FM harus dikerjakan oleh petugas khusus 
dengan tingkat ketelitian yang tinggi. Masalah juga dihadapi oleh bagian marketing yaitu lamanya waktu mencari slot jadwal yang masih kosong, selain itu petugas siaran harus mencari iklan yang diputar didalam komputer sehingga menyebabkan keterlambatan pemutaran atau durasi siaran menjadi molor diluar jadwal yang di tentukan dan tentunya durasi dari iklan harus di sesuaikan dengan program siaran agar bisa berjalan sesuai jadwal pada Most FM. Penjadwalan (schedulling) adalah pengaturan proses pengambilan waktu dari suatu operasi. Penjadwalan mencakup kegiatan megalokasikan fasilitas, peralatan maupun tenaga kerja bagi suatu kegiatan operasi. Penjadwalan selalu berkaitan dengan pengalokasian sumber daya yang ada pada jangka waktu tertentu, hal tersebut adalah proses pengambilan keputusan yang bertujuan sebagai optimasi.

Pada penelitian ini menggunakan algoritma genetika pada penjadwalan jeda iklan di Most FM. Algoritma genetika merupakan pendekatan komputasional untuk menyelesaikan masalah yang dimodelkan dengan proses biologi dari evolusi, meliputi seleksi, crossover, dan mutasi. Dengan demikian pada penelitian ini menggunakan algoritma genetika dalam proses untuk mengatur penjadwalan suatu aktifitas yang berulang, pembagian slot-slot dan jam tayangan prime time dan reguler time dan juga penjadwalan jeda iklan radio pada Most FM.

Fitria Larantika, Sistem penjadwalan otomatis dalam menentukan jadwal matakuliah menggunakan algoritma genetika di fakultas sains dan teknologi. Penyusunan jadwal mata kuliah yang dapat menghasilkan jadwal yang berurutan dalam satu hari penjadwalan [1]. Pada penelitian Ridha Apriani, Algoritma genetic auntuk menyelesaikan permasalahan penjadwalan perkuliahan dan praktikum. Dengan algoritma genetika dapat mencari solusi penjadwalan perkuliahan dan praktikum dengan waktu yang lebih cepat [2]. Hasil pengujian dengan input nilai parameter yang sama atau berbeda, proses penjadwalan menghasilkan hasil generasi dan iterasi yang berbeda - beda. Pada penelitian Justina Adamanti, Penyelesaian masalah penjadwalan mata kuliah di fakultas matematika dan ilmu pengetahuan alam Universitas Gadjah Mada dengan menggunakan algoritma genetika. Dengan menggunakan algoritma genetika program dapat menghasilkan suatu jadwal kuliah. Berdasarkan hasil uji parameter, metode seleksi terbaik adalah seleksi turnamen, metode perkawinan silang terbaik adalah perkawinan silang banyak titik, tanpa elitsm umumnya lebih cepat menyelesaikan penjadwalan dan jumlah populasi yang lebih baik untuk model kromosom masalah penjadwalan jeda iklan yang memiliki gen pada individu, tetapi tidak lebih cepat dalam waktu dibandingkan dengan jumlah populasi yang lebih sedikit [3].

\section{METODE PENELITIAN}

\subsection{Artificial Intelligence}

Kecerdasan Buatan (Artificial Intelligence) merupakan salah satu bagian dari ilmu komputer yang mempelajari bagaimana membuat mesin (komputer) dapat melakukan pekerjaan seperti dan sebaik yang dilakukan oleh manusia bahkan bisa lebih baik daripada yang dilakukan manusia. Untuk mengetahui dan memodelkan prosesproses berpikir manusia dan mendesain mesin agar dapat menirukan perilaku manusia. Cerdas, berarti memiliki pengetahuan ditambah pengalaman, penalaran (bagaimana membuat keputusan dan mengambil tindakan), moral yang baik. Manusia cerdas (pandai) dalam menyelesaikan permasalahan karena manusia mempunyai pengetahuan dan pengalaman. Pengetahuan diperoleh dari belajar. Semakin banyak bekal pengetahuan yang dimiliki tentu akan lebih mampu menyelesaikan permasalahan. Tapi bekal pengetahuan saja tidak cukup, manusia juga diberi akal untuk melakukan penalaran,mengambil kesimpulan berdasarkan pengetahuan dan pengalaman yang dimiliki. Tanpa memiliki kemampuan untuk menalar dengan baik, manusia dengan segudang pengalaman dan pengetahuan tidak akan dapat menyelesaikan masalah dengan baik. Demikian juga dengan kemampuan menalar yang sangat baik,namun tanpa bekal pengetahuan dan pengalaman yang memadai, manusia juga tidak akan bisa menyelesaikan masalah dengan baik. Demikin juga agar mesin bisa cerdas (bertindak seperti dan sebaik manusia) maka harus diberi bekal pengetahuan, sehingga mempunyai kemampuan untuk menalar.

\subsection{Algoritma Genetika}

Sejak pertama kali dirintis oleh John Holland pada tahun 1960-an, algoritma genetika telah dipelajari, diteliti, dan diaplikasikan secara luas pada berbagai bidang.Algoritma banyak digunakan pada masalah praktis yang berfokus pada pencarian parameter-parameter optimal [3]. Algoritma genetika merupakan teknik pencarian nilai optimum secara stochastic berdasarkan mekanisme seleksi alam algoritma genetika berbeda dengan teknik konvergensikonvensional yang lebih bersifat deterministic. Dalam proses evolusi, individu secara terus menerus mengalami perubahan gen untuk menyesuaikan dengan lingkungan hidupnya

\subsection{Periklanan}

Iklan adalah bagian dari bauran promosi (promotion mix) dan bauran promosi adalah bagian dari bauran pemasaran (marketing mix). Secara sederhana iklan didefinisikan sebagai pesan yang menawarkan suatu produk yang ditujukan kepada masyarakat lewat suatu media [5]. 


\section{ANALISA DAN PEMBAHASAN}

\subsection{Analisa Masalah}

Analisa masalah dalam penjadwalan iklan adalah masalah menempatkan waktu dan ruangan kepada sejumlah iklan dengan beberapa variabel tanggal, jam, menit, durasi dan frekuensipemutaran. Penempatan waktu kepada iklan dengan memperhatikan sejumlah aturan yang berhubungan dengan kapasitas dan lokasi dari ruang yang tersedia, waktu bebas yang diperlukan dan sejumlah aturan lain yang berkaitan. Komponen-komponen utama dari penjadwalan sebuah iklan adalah tanggal, jam, menit, durasi, frekuensi, dan menentukan waktu penayangan sesuai slot-slot yang ada dan pemutaran yang ditawarkan. Hasil dari proses penjadwalan merupakan pengelompokan komponen-komponen utama secara bersama-sama dengan memperhatikan aturan-aturan yang telah ditetapkan dalampenjadwalan. Masalah juga dihadapi oleh bagian marketing yaitu lamanya waktu mencari slot jadwal yang masih kosong, selain itu petugas siaran harus mencari iklan yang diputar didalam komputer sehingga menyebabkan keterlambatan pemutaran atau durasi siaran menjadi molor diluar jadwal yang di tentukan dan tentunya durasi dari iklan harus di sesuaikan dengan program siaran agar bisa berjalan sesuai jadwal pada Most FM.

Penjadwalan (schedulling) adalahpengaturan proses pengambilan waktu dari suatu operasi. Penjadwalan mencakup kegiatan mengalokasikan fasilitas, peralatan maupun tenaga kerja bagi suatu kegiatan operasi. Penjadwalan selalu berkaitan dengan pengalokasian sumber daya yang ada pada jangka waktu tertentu, hal tersebut adalah proses pengambilan keputusan yang bertujuan sebagai optimasi. Masalah dalam penjadwalan iklan adalah masalah menempatkan waktu dan ruangan kepada sejumlah iklan dengan beberapa variabel tanggal, jam, menit, durasi dan frekuensi pemutaran. Penempatan waktu kepada iklan dengan memperhatikan sejumlah aturan yang berhubungan dengan kapasitas dan lokasi dari ruang yang tersedia, waktu bebas yang diperlukan dan sejumlah aturan lain yang berkaitan.

Pemutaran iklan yang dilakukan pada jadwal siar radio yaitu antara jam 5 pagi sampai jam 00:00 malam dengan aturan setiap 15 menit disediakan 3 slot pemutaran iklan dengan durasi per iklan maksimum 1 menit. Jadi jika waktu siar radio per hari ada 19 jam, maka jumlah maksimum iklan per hari yang dapat ditayangkan adalah 76 iklan. Rancangan Pemasukan Iklan ini berfungsi untuk memilih iklan yang akan dijadwalkan sesuai dengan jenis waktu pada stasiun radio komersialiklan. Jadi panjang kromosom itu sendiri dari satu individu adalah sebanyak 30 kromosomdari jumlah iklan yang akan disiarkan sesuai data yang ada dan yang diperlukan. Sedangkan panjang satu kromosom terdiri dari 3 gen. Populasi awal tersebut kemudian dibangkitkan secara acak untuk selanjutnya dilakukan proses evaluasi setiap kromosomnya. Representasi kromosom dalam penelitian ini dapa dijelaskan pada Tabel 1.

Tabel 1. IDPenjadwalan

\begin{tabular}{cccc}
\hline Kromosom & IDIklan & IDHari & IDWaktu \\
\hline 1 & 0022 & 3 & 12 \\
2 & 0006 & 3 & 12 \\
3 & 0010 & 1 & 14 \\
4 & 0002 & 1 & 11 \\
5 & 0005 & 4 & 29 \\
6 & 0013 & 7 & 03 \\
7 & 0014 & 5 & 08 \\
8 & 0008 & 6 & 14 \\
9 & 0012 & 6 & 03 \\
10 & 0007 & 4 & 21 \\
11 & 0015 & 2 & 18 \\
12 & 0009 & 1 & 07 \\
13 & 0024 & 4 & 06 \\
14 & 0017 & 3 & 22 \\
15 & 0001 & 7 & 12 \\
16 & 0019 & 1 & 17 \\
17 & 0004 & 7 & 14 \\
18 & 0007 & 5 & 15 \\
19 & 0028 & 1 & 45 \\
20 & 0011 & 5 & 04 \\
21 & 0030 & 2 & 09 \\
22 & 0025 & 3 & 12 \\
23 & 0016 & 6 & 02 \\
24 & 0018 & 6 & 07 \\
25 & 0023 & 4 & 08 \\
26 & 0021 & 7 & 19 \\
27 & 0029 & 2 & 23 \\
\hline
\end{tabular}


Building of Informatics, Technology and Science (BITS)

Volume 2, No 2, December 2020 Page 99-108

ISSN 2684-8910 (media cetak)

ISSN 2685-3310 (media online)

\begin{tabular}{cccc}
\hline Kromosom & IDIklan & IDHari & IDWaktu \\
\hline 28 & 0020 & 4 & 07 \\
29 & 0027 & 1 & 05 \\
30 & 0026 & 6 & 05 \\
\hline
\end{tabular}

\subsection{Penerapan Genetika}

Berikut adalah contoh aplikasi algoritma genetika yang digunakan untuk menyelesaikan masalah kombinasi. Misalkan ada persamaan $a+2 b+3 c+4 d=30$, kita mencari nilai $a, b, c$, dan d yang memenuhi persamaan diatas dan sesuai dengan kebutuhannya. Kita mencoba menggunakan algoritma genetika untuk menyelesaikan permasalahan diatas.

\section{Inisialisasi}

Proses inisialisasi dilakukan dengan cara memberikan nilai awal gen-gen dengan nilai acak sesuai batasan yang telah ditentukan. Maka kita tentukan jumlah populasi adalah 30, maka:

Chromosome[1] $=[\mathrm{a} ; \mathrm{b} ; \mathrm{c} ; \mathrm{d}]=[22 ; 03 ; 12]$

Chromosome $[2]=[a ; b ; c ; d]=[06 ; 03 ; 12]$

Chromosome $[3]=[\mathrm{a} ; \mathrm{b} ; \mathrm{c} ; \mathrm{d}]=[10 ; 01 ; 14]$

Chromosome $[4]=[a ; b ; c ; d]=[02 ; 01 ; 11]$

Chromosome $[5]=[\mathrm{a} ; \mathrm{b} ; \mathrm{c} ; \mathrm{d}]=[05 ; 04 ; 29]$

Chromosome $[6]=[\mathrm{a} ; \mathrm{b} ; \mathrm{c} ; \mathrm{d}]=[13 ; 07 ; 03]$

Chromosome[7] $=[\mathrm{a} ; \mathrm{b} ; \mathrm{c} ; \mathrm{d}]=[14 ; 05 ; 08]$

Chromosome $[8]=[\mathrm{a} ; \mathrm{b} ; \mathrm{c} ; \mathrm{d}]=[08 ; 06 ; 14]$

Chromosome [9] $=[\mathrm{a} ; \mathrm{b} ; \mathrm{c} ; \mathrm{d}]=[12 ; 06 ; 03]$

Chromosome[10] $=[\mathrm{a} ; \mathrm{b} ; \mathrm{c} ; \mathrm{d}]=[07 ; 04 ; 21]$

Chromosome[11] $=[\mathrm{a} ; \mathrm{b} ; \mathrm{c} ; \mathrm{d}]=[15 ; 02 ; 18]$

Chromosome[12] $=[\mathrm{a} ; \mathrm{b} ; \mathrm{c} ; \mathrm{d}]=[09 ; 01 ; 07]$

Chromosome[13] $=[\mathrm{a} ; \mathrm{b} ; \mathrm{c} ; \mathrm{d}]=[24 ; 04 ; 06]$

Chromosome[14] $=[\mathrm{a} ; \mathrm{b} ; \mathrm{c} ; \mathrm{d}]=[17 ; 03 ; 22]$

Chromosome[15] $=[\mathrm{a} ; \mathrm{b} ; \mathrm{c} ; \mathrm{d}]=[01 ; 07 ; 12]$

Chromosome[16] $=[\mathrm{a} ; \mathrm{b} ; \mathrm{c} ; \mathrm{d}]=[19 ; 01 ; 17]$

Chromosome[17] $=[\mathrm{a} ; \mathrm{b} ; \mathrm{c} ; \mathrm{d}]=[04 ; 05 ; 02]$

Chromosome[18] $=[\mathrm{a} ; \mathrm{b} ; \mathrm{c} ; \mathrm{d}]=[07 ; 05 ; 15]$

Chromosome[19]=[a;b;c;d] $=[28 ; 01 ; 45]$

Chromosome[20] $=[\mathrm{a} ; \mathrm{b} ; \mathrm{c} ; \mathrm{d}]=[11 ; 05 ; 04]$

Chromosome[21] $=[\mathrm{a} ; \mathrm{b} ; \mathrm{c} ; \mathrm{d}]=[30 ; 02 ; 09]$

Chromosome[22] $=[\mathrm{a} ; \mathrm{b} ; \mathrm{c} ; \mathrm{d}]=[25 ; 03 ; 12]$

Chromosome[23] $=[\mathrm{a} ; \mathrm{b} ; \mathrm{c} ; \mathrm{d}]=[16 ; 06 ; 02]$

Chromosome[24]=[a;b;c;d] $=[18 ; 06 ; 07]$

Chromosome[25] $=[\mathrm{a} ; \mathrm{b} ; \mathrm{c} ; \mathrm{d}]=[23 ; 04 ; 08]$

Chromosome[26] $=[\mathrm{a} ; \mathrm{b} ; \mathrm{c} ; \mathrm{d}]=[21 ; 07 ; 19]$

Chromosome[27] $=[\mathrm{a} ; \mathrm{b} ; \mathrm{c} ; \mathrm{d}]=[29 ; 02 ; 23]$

Chromosome[28]=[a;b;c;d] $=[20 ; 04 ; 07]$

Chromosome[29] $=[\mathrm{a} ; \mathrm{b} ; \mathrm{c} ; \mathrm{d}]=[27 ; 01 ; 05]$

Chromosome[30] $=[\mathrm{a} ; \mathrm{b} ; \mathrm{c} ; \mathrm{d}]=[26 ; 06 ; 05]$

\section{Evaluasi Chromosome}

Permasalahan yang ingin diselesaikan adalah nilai variabel a, b, c, dan d yang memenuhi persamaan $a+2 b+3 c+4 d$ $=30$, sesuai dengan kebutuhan yang akan digunakan. Maka fungsi_objektif yang dapat digunakan untuk mendapatkan solusi adalah fungsi_objektif (chromosome) $=[(a+2 b+3 c)=30]$. Kita hitung fungsi_objektif dari chromosome yang telah dibangkitkan:

Inisialisasi

Proses inisialisasi dilakukan dengan cara memberikan nilai awal gen-gen dengan nilai acak sesuai batasan yang telah ditentukan.

Maka kita tentukan jumlah populasi adalah 30, maka:

fungsi_objektif(chromosome[1]) = $\operatorname{Abs}((22+2 * 3+3 * 12)-30)$

$$
\begin{aligned}
& =\operatorname{Abs}((22+6+36)-30) \\
& =\operatorname{Abs}(64-30) \\
& =34
\end{aligned}
$$

fungsi_objektif(chromosome[2]) = Abs $((6+2 * 3+3 * 12)-30)$

$$
\begin{aligned}
& =\operatorname{Abs}((6+6+36)-30) \\
& =\operatorname{Abs}(48-30) \\
& =18
\end{aligned}
$$


Building of Informatics, Technology and Science (BITS)

Volume 2, No 2, December 2020 Page 99-108

ISSN 2684-8910 (media cetak)

ISSN 2685-3310 (media online)

fungsi_objektif(chromosome[3]) $=\operatorname{Abs}((10+2 * 1+3 * 14)-30)$

$$
\begin{aligned}
& =\operatorname{Abs}((10+2+42)-30) \\
& =\operatorname{Abs}(54-30)
\end{aligned}
$$

$$
=24
$$

fungsi_objektif(chromosome[4]) $=\operatorname{Abs}((5+2 * 1+3 * 11)-30)$

$$
=\operatorname{Abs}((5+2+33)-30)
$$$$
=\operatorname{Abs}(40-30)
$$$$
=10
$$

fungsi_objektif(chromosome[5]) = Abs $((2+2 * 4+3 * 29)-30)$

$$
\begin{aligned}
& =\operatorname{Abs}((2+8+87)-30) \\
& =\operatorname{Abs}(97-30)
\end{aligned}
$$$$
=67
$$

Rata-rata dari fungsi objektif adalah:

rata-rata $=$

$(34+18+24+10+67+6+18+32+3+48+43+2+10+59+21+42+30+32+135+3+31+37+4+21+25+62+72+19+14+23) /$ 30

$$
\begin{aligned}
& =939 / 30 \\
& =31.3
\end{aligned}
$$

\section{Seleksi Chromosome}

Proses Seleksi Chromosome dilakukan dengan cara membuat chromosome yang mempunyai fungsi_objektif kecil mempunyai kemungkinan terpilih yang besar atau mempunyai nilai probabilitas yang tinggi. Untuk itu dapat digunakan fungsi fitness $=(\mathbf{1} /(\mathbf{1}+\mathbf{f u n g s i}$ objektif $))$, fungsi_objektif perlu ditambah 1 untuk menghindari kesalahan program yang diakibatkan pembagian oleh 0 .

$\begin{aligned} \text { fitness[1] } & =1 / \text { fungsi_objektif[1]+1) } \\ & =1 / 35 \\ & =0.02857 \\ \text { fitness[2] } & =1 /(\text { fungsi_objektif[2]+1) } \\ & =1 / 19 \\ & =0.05263 \\ \text { fitness[3] } & =1 /(\text { fungsi_objektif[3]+1) } \\ & =1 / 25 \\ & =0.04 \\ \text { fitness[4] } & =1 /(\text { fungsi_objektif[4]+1) } \\ & =1 / 11 \\ \text { fitness[5] } & =0.0909 \\ & =1 /(\text { fungsi_objektif[5]+1) } \\ & =1 / 68 \\ & =0.0147\end{aligned}$

Total fitness $=0.02857+0.05263+0.04+0.0909+0.0147+0.1428+0.0526+0.0303+0.25+0.0204+0.227$ $+0.333+0.0909+0.01666+0.0454+0.0232+0.0322+0.0303+0.0073+0.25+0.03125+0.0263+0.02+$ $0.0454+0.0384+0.0158+0.01408+0.05+0.0666+0.0416=2.12829$

Rumus untuk mencari probabilitas: $P[i]=$ fitness $[i] /$ total_fitness

$$
\begin{aligned}
\mathrm{P}[1] & =0.02857 / 2.12829 \\
& =0.0134 \\
\mathrm{P}[2] & =0.05263 / 2.12829 \\
& =0.0247 \\
\mathrm{P}[3] & =0.04 / 2.12829 \\
& =0.0187 \\
\mathrm{P}[4] & =0.0909 / 2.12829 \\
\mathrm{P}[5] & =0.0427 \\
& =0.0147 / 2.12829 \\
& =0.0069
\end{aligned}
$$

Dari probabilitas diatas dapat kita lihat kalau chromosome ke 12 yang mempunyai fitness paling besar maka chromosome tersebut mempunyai probabilitas untuk terpilih pada generasi selanjutnya lebih besar dari chromosome lainnya. Untuk proses seleksi kita gunakan roulette wheel, untuk itu kita harus mencari dahulu nilai kumulatif probabilitasnya:

$$
\begin{array}{ll}
\mathrm{C}[1] & =0.0134 \\
\mathrm{C}[2] & =0.0134+0.0247=0.0381 \\
\mathrm{C}[3] & =0.0134+0.0247+0.0187=0.0568 \\
\mathrm{C}[4] & =0.0134+0.0247+0.0187+0.0427=0.0995 \\
\mathrm{C}[5] & =0.0134+0.0247+0.0187+0.0427+0.0069=0.713
\end{array}
$$


Setelah dihitung cumulative probabilitasnya maka proses seleksi menggunakan roulete-wheel dapat dilakukan. Prosesnya adalah dengan membangkitkan bilangan acak $\mathrm{R}$ dalam range $0-1$.Jika $\mathrm{R}[\mathrm{k}]<\mathrm{C}[1]$ maka pilih chromosome 1 sebagai induk, selain itu pilih chromosome ke-k sebagai induk dengan syarat $\mathrm{C}[\mathrm{k}-1]<\mathrm{R}<\mathrm{C}[\mathrm{k}]$. Kita putar roulete wheel sebanyak jumlah populasi yaitu 30 kali (bangkitkan bilangan acak R) dan pada tiap putaran, kita pilih satu chromosome untuk populasi baru.

Tabel 2. Pembangkitan Cromosome

\begin{tabular}{cccccc}
\hline Kromosom & Fitness & Kromosom & Fitness & Rank \\
\hline A & 1 & B & 5 & 1 \\
B & 5 & C & 3 & 2 \\
C & 3 & D & 3 & 3 \\
D & 3 & E & 1 & 4 \\
E & 2 & & A & 2 & 5 \\
\hline
\end{tabular}

$\begin{array}{ll}\mathrm{R}[1]=0.6025 & \mathrm{R}[16]=0.9108 \\ \mathrm{R}[2]=0.3303 & \mathrm{R}[17]=0.7003 \\ \mathrm{R}[3]=0.8353 & \mathrm{R}[18]=0.8499 \\ \mathrm{R}[4]=0.4464 & \mathrm{R}[19]=0.2129 \\ \mathrm{R}[5]=0.174 & \mathrm{R}[20]=0.7145 \\ \mathrm{R}[6]=0.0995 & \mathrm{R}[21]=0.0134 \\ \mathrm{R}[7]=0.0670 & \mathrm{R}[22]=0.8622 \\ \mathrm{R}[8]=0.9794 & \mathrm{R}[23]=0.6852 \\ \mathrm{R}[9]=0.0381 & \mathrm{R}[24]=0.3398 \\ \mathrm{R}[10]=0.1987 & \mathrm{R}[25]=0.8715 \\ \mathrm{R}[11]=0.9482 & \mathrm{R}[26]=0.653 \\ \mathrm{R}[12]=0.6743 & \mathrm{R}[27]=0.9182 \\ \mathrm{R}[13]=0.8928 & \mathrm{R}[28]=0.713 \\ \mathrm{R}[14]=0.9989 & \mathrm{R}[29]=0.9248 \\ \mathrm{R}[15]=0.0568 & \mathrm{R}[30]=0.7179\end{array}$

Acak pertama R[1] adalah lebih besar dari C[1] dan lebih kecil daripada C[2] maka pilih chromosome[2] sebagai chromosome pada populasi baru, dari bilangan acak yang telah dibangkitkan diatas maka populasi chromosome baru hasil proses seleksi adalah:

chromosome[1] $=$ chromosome[12]

chromosome[2] $=$ chromosome[9]

chromosome[3] $=$ chromosome[20]

chromosome[4] $=$ chromosome[11]

chromosome[5] $=$ chromosome[6]

chromosome[6] $=$ chromosome[4]

chromosome[7] $=$ chromosome[13]

chromosome[8] $=$ chromosome[29]

chromosome[9] $=$ chromosome[2]

chromosome[10] $=$ chromosome[7]

chromosome[11] $=$ chromosome[28]

chromosome[12] $=$ chromosome[15]

chromosome[13] $=$ chromosome[24]

chromosome [14 $]=$ chromosome [30]

chromosome[15] $=$ chromosome[3]

chromosome[16] $=$ chromosome[25]

chromosome[17] $=$ chromosome [17]

chromosome[18] $=$ chromosome [21]

chromosome[19] $=$ chromosome [8]

chromosome[20] $=$ chromosome [18]

chromosome[21] $=$ chromosome[1]

chromosome[22] $=$ chromosome[22]

chromosome[23] $=$ chromosome [16]

chromosome[24] $=$ chromosome $[10]$

chromosome[25] $=$ chromosome [23]

chromosome[26] $=$ chromosome [14]

chromosome[27] $=$ chromosome[26]

chromosome[28] $=$ chromosome [5]

chromosome[29] $=$ chromosome[27]

chromosome[30] $=$ chromosome[19] 
Building of Informatics, Technology and Science (BITS)

Volume 2, No 2, December 2020 Page 99-108

ISSN 2684-8910 (media cetak)

ISSN 2685-3310 (media online)

Dari proses pembangkitan maka diketahui hasil Chromosome baru hasil proses seleksi:

chromosome $[1]=[09 ; 01 ; 07]$

chromosome $[2]=[12 ; 06 ; 03]$

chromosome[3] $=[11 ; 05 ; 04]$

chromosome $[4]=[15 ; 02 ; 18]$

chromosome $[5]=[13 ; 07 ; 03]$

chromosome $[6]=[05 ; 01 ; 11]$

chromosome[7] $=[24 ; 04 ; 06]$

chromosome $[8]=[27 ; 01 ; 05]$

chromosome $[9]=[06 ; 03 ; 12]$

chromosome $[10]=[14 ; 05 ; 08]$

chromosome $[11]=[20 ; 04 ; 07]$

chromosome $[12]=[01 ; 07 ; 12]$

chromosome $[13]=[18 ; 06 ; 07]$

chromosome $[14]=[26 ; 06 ; 05]$

chromosome $[15]=[10 ; 01 ; 14]$

chromosome $[16]=[23 ; 04 ; 08]$

chromosome $[17]=[04 ; 07 ; 14]$

chromosome $[18]=[30 ; 02 ; 09]$

chromosome $[19]=[08 ; 06 ; 14]$

chromosome $[20]=[07 ; 05 ; 15]$

chromosome $[21]=[22 ; 03 ; 12]$

chromosome $[22]=[25 ; 03 ; 12]$

chromosome $[23]=[19 ; 01 ; 17]$

chromosome $[24]=[07 ; 04 ; 21]$

chromosome $[25]=[16 ; 06 ; 02]$

chromosome $[26]=[17 ; 03 ; 22]$

chromosome $[27]=[21 ; 07 ; 19]$

chromosome $[28]=[02 ; 04 ; 29]$

chromosome $[29]=[29 ; 02 ; 23]$

chromosome $[30]=[28 ; 01 ; 45]$

\section{Crossover}

Setelah proses seleksi maka proses selanjutnya adalah proses crossover. Metode yang digunakan salah satunya adalah one-cut point, yaitu memilih secara acak satu posisi dalam chromosome induk kemudian saling menukar gen. Chromosome yang dijadikan induk dipilih secara acak dan jumlah chromosome yang mengalami crossover dipengaruhi oleh parameter crossover_rate ( $\rho c)$.

Setelah ditentukan crossover probability adalah sebesar 31\%, maka diharapkan dalam satu generasi ada $>50 \%$ Chromosome ( 3 chromosome) dari satu generasi mengalami proses crossover. Prosesnya adalah sebagai berikut:

Pertama kita bangkitkan bilangan acak R sebanyak jumlah populasi.

$\begin{array}{ll}\mathrm{R}[1]=0.2129 & \mathrm{R}[16]=0.8353 \\ \mathrm{R}[2]=0.9182 & \mathrm{R}[17]=0.7179 \\ \mathrm{R}[3]=0.174 & \mathrm{R}[18]=0.0568 \\ \mathrm{R}[4]=0.653 & \mathrm{R}[19]=0.3398 \\ \mathrm{R}[5]=0.9989 & \mathrm{R}[20]=0.713 \\ \mathrm{R}[6]=0.6852 & \mathrm{R}[21]=0.3303 \\ \mathrm{R}[7]=0.1987 & \mathrm{R}[22]=0.0670 \\ \mathrm{R}[8]=0.9108 & \mathrm{R}[23]=0.9248 \\ \mathrm{R}[9]=0.9108 & \mathrm{R}[24]=0.4464 \\ \mathrm{R}[10]=0.6025 & \mathrm{R}[25]=0.8928 \\ \mathrm{R}[11]=0.9794 & \mathrm{R}[26]=0.0995 \\ \mathrm{R}[12]=0.8499 & \mathrm{R}[27]=0.9482 \\ \mathrm{R}[13]=0.0134 & \mathrm{R}[28]=0.0381 \\ \mathrm{R}[14]=0.7003 & \mathrm{R}[29]=0.7145 \\ \mathrm{R}[15]=0.8715 & \mathrm{R}[30]=0.0134\end{array}$

Maka Chromosome ke $\mathrm{k}$ akan dipilih sebagai induk jika $\mathrm{R}[\mathrm{k}]<\rho \mathrm{c}$, dari bilangan acak $\mathrm{R}$ diatas maka yang dijadikan induk adalah chromosome[1], chromosome[3],

chromosome[4], chromosome[7], chromosome[10], chromosome[13],

chromosome[18], chromosome[19], chromosome[20], chromosome[21],

chromosome[22], chromosome[24], chromosome[26], chromosome[28],

chromosome[30]. 
Building of Informatics, Technology and Science (BITS)

Volume 2, No 2, December 2020 Page 99-108

ISSN 2684-8910 (media cetak)

ISSN 2685-3310 (media online)

Setelah melakukan pemilihan induk proses selanjutnya adalah menentukan posisi crossover. Ini dilakukan dengan cara membangkitkan bilangan acak dengan batasan 1 sampai (panjang chromosome-1), dalam kasus ini bilangan acak yang dibangkitkan adalah $1-15$. Misalkan didapatkan posisi crossover adalah 1 maka chromosome induk akan dipotong mulai gen ke 1 kemudian potongan gen tersebut saling ditukarkan antar induk.

chromosome[1] $><$ chromosome[3]

chromosome[3] $><$ chromosome[4]

chromosome[4] $><$ chromosome[7]

chromosome[7] $><$ chromosome[10]

chromosome[10] $><$ chromosome[13]

chromosome[13] $><$ chromosome[18]

chromosome[18] $><$ chromosome[19]

chromosome[19] $><$ chromosome[20]

chromosome[20] $><$ chromosome[21]

chromosome[21] $><$ chromosome[22]

chromosome[22] $><$ chromosome[24]

chromosome[24] $><$ chromosome[26]

chromosome[26] $><$ chromosome[28]

chromosome[28] $><$ chromosome[30]

chromosome[30] $><$ chromosome[1]

$\mathrm{C}[1]=1$

$\mathrm{C}[2]=3$

$\mathrm{C}[3]=4$

$\mathrm{C}[4]=7$

$\mathrm{C}[5]=10$

$\mathrm{C}[6]=1$

$\mathrm{C}[7]=18$

$C[8]=19$

$\mathrm{C}[9]=20$

$C[10]=21$

$\mathrm{C}[11]=22$

$\mathrm{C}[12]=24$

$\mathrm{C}[13]=26$

$\mathrm{C}[14]=28$

$\mathrm{C}[15]=30$

offspring [1] $=$ chromosome[1] $><$ chromosome[3]

$=[09 ; 01 ; 07]\rangle\langle[11 ; 05 ; 04]$

$=[09 ; 05 ; 04]$

offspring [3] = chromosome[3] $><$ chromosome [4]

$=[11 ; 05 ; 04]\rangle\langle[15 ; 02 ; 18]$

$=[11 ; 02 ; 18]$

offspring [4] $=$ chromosome [4] $><$ chromosome[7]

$=[15 ; 02 ; 18]\rangle\langle[24 ; 05 ; 08]$

$=[15 ; 05 ; 08]$

offspring[7] $=$ chromosome[7] $><$ chromosome[10]

$=[24 ; 05 ; 08]\rangle\langle[14 ; 05 ; 08]$

$=[24 ; 05 ; 08]$

offspring $[10]=$ chromosome $[10]\rangle\langle$ chromosome $[1]$

$=[14 ; 05 ; 08]\rangle\langle[09 ; 01 ; 07]$

$=[14 ; 01 ; 07]$

offspring[1] $=$ chromosome[1] $><$ chromosome[18]

$=[09 ; 01 ; 07]\rangle\langle[30 ; 02 ; 09]$

$=[09 ; 02 ; 09]$

offspring $[18]=$ chromosome $[18]><$ chromosome $[19]$

$=[30 ; 02 ; 09]><[08 ; 06 ; 14]$

$=[30 ; 06 ; 14]$

offspring [19] $=$ chromosome $[19]><$ chromosome[20]

$=[08 ; 06 ; 14]><[07 ; 05 ; 15]$

$=[08 ; 05 ; 15]$

offspring[20] $=$ chromosome[20] $><$ chromosome[21]

$=[07 ; 05 ; 15]\rangle\langle[22 ; 03 ; 12]$

$=[07 ; 03 ; 12]$

offspring $[21]=$ chromosome[21] $><$ chromosome $[22]$ 


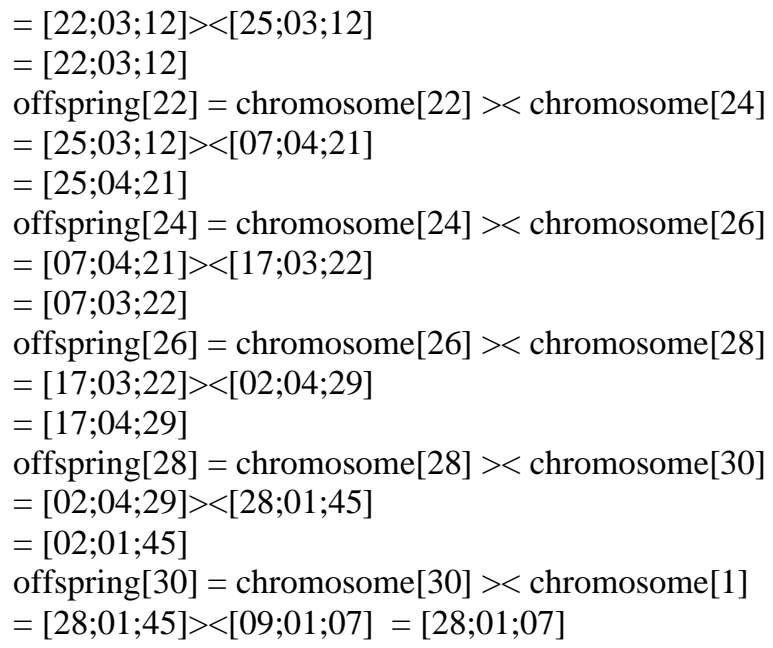

\section{Mutasi}

Jumlah chromosome yang mengalami mutasi dalam satu populasi ditentukan oleh parameter mutation_rate. Proses mutasi dilakukan dengan cara mengganti satu gen yang terpilih secara acak dengan suatu nilai baru yang didapat secara acak. total_gen $=($ jumlah gen dalam chromosome $) *$ jumlah populasi

$=3 * 30=90$

Untuk memilih posisi gen yang mengalami mutasi dilakukan dengan cara membangkitkan bilangan integer acak antara 1 sampai total_gen, yaitu 1 sampai 90. Jika bilangan acak yang kita bangkitkan lebih kecil daripada variabel mutation_rate $(\mathrm{\rho m})$ maka pilih posisi tersebut sebagai sub-chromosome yang mengalami mutasi. Misal $\rho$ m kita tentukan $10 \%$ maka diharapkan ada $10 \%$ dari total_gen yang mengalami populasi:

jumlah mutasi $=0.1 * 90=9$

Setelah kita bangkitkan bilangan acak terpilih posisi gen $2,1,21,9,5,6,16,7$, dan 8 yang mengalami mutasi. Maka nilai gen pada posisi tersebut kita ganti dengan bilangan acak 0-30. Setelah dihihitung maka bilangan acak yang terbangkitkan setelah mengalami proses mutasi adalah:

$1,2,5,6,7,8,9,16$ dan 21

chromosome $[1]=[09 ; 05 ; 04]$

chromosome $[2]=[12 ; 05 ; 03]$

chromosome $[3]=[11 ; 02 ; 18]$

chromosome $[4]=[06 ; 02 ; 12]$

chromosome $[5]=[11 ; 05 ; 12]$

chromosome $[6]=[05 ; 05 ; 11]$

chromosome [13] $=[18 ; 06 ; 07]$

chromosome $[14]=[26 ; 06 ; 05]$

chromosome $[15]=[10 ; 01 ; 14]$

chromosome $[16]=[23 ; 04 ; 08]$

chromosome $[17]=[04 ; 07 ; 14]$

chromosome $[18]=[30 ; 06 ; 14]$

chromosome $[19]=[08 ; 05 ; 15]$

chromosome $[20]=[07 ; 03 ; 12]$

chromosome $[21]=[11 ; 02 ; 18]$

$$
\begin{aligned}
& \text { chromosome[7] }=[05 ; 04 ; 08] \\
& \text { chromosome[8] }=[27 ; 03 ; 12] \\
& \text { chromosome[9] }=[06 ; 03 ; 12] \\
& \text { chromosome[10] }=[14 ; 01 ; 07] \\
& \text { chromosome[11] }=[20 ; 04 ; 07] \\
& \text { chromosome[12] }=[01 ; 07 ; 12] \\
& \text { chromosome[22] }=[25 ; 04 ; 21] \\
& \text { chromosome[23] }=[19 ; 01 ; 17] \\
& \text { chromosome[24] }=[07 ; 03 ; 22] \\
& \text { chromosome[25] }=[16 ; 06 ; 02] \\
& \text { chromosome[26] }=[17 ; 04 ; 29] \\
& \text { chromosome[27] }=[21 ; 07 ; 19] \\
& \text { chromosome[28] }=[02 ; 01 ; 45] \\
& \text { chromosome[29] }=[29 ; 02 ; 23] \\
& \text { chromosome[30] }=[28 ; 01 ; 07]
\end{aligned}
$$

Mutiah, Copyright (C) 2020, BITS | Page 107 
Setelah selesai dilakukan evaluasi chromosome dengan berbagai tahapan sesuai dengan rumus maka diketahui nilai-nilai chromosomenya dan memasukkan nilainya kemudian kita lakukan penjdwalan iklan sesuai dengan cromosome diatas untuk ditentukan apakah algoritma genetika dapat digunakan dan diterapkan pada penjadwalan iklan pada Most FM. Hasil dari penjadwalan setelah terjadi fungsi acak dapat kita lihat pada tabel berikut:

Tabel 3. Penjadwalan iklan

\begin{tabular}{cccc}
\hline Kromosom & IDIklan & IDHari & IDWaktu \\
\hline 1 & 0012 & 5 & 3 \\
2 & 0009 & 5 & 4 \\
3 & 0011 & 2 & 15 \\
4 & 0006 & 3 & 12 \\
5 & 0011 & 5 & 12 \\
6 & 0005 & 5 & 11 \\
7 & 0023 & 4 & 8 \\
8 & 0005 & 4 & 8 \\
9 & 0027 & 3 & 12 \\
\hline
\end{tabular}

Dari tabel diatas dapat diketahui bahwa algoritma genetika tidak dapat diterapkan dalam penjadwalan iklan pada Most FM karena hasil penjadwalannya tidak beraturan dan setelah dimutasi penjadwalan menjadi lebih sedikit jumlahnya. Karena populasi dipengaruhi fungsi acak sehingga hasil yang diperoleh pada proses penjadwalan jeda iklan tidak optimal dan algoritma genetika pada dasarnya terbentuk dari partikel terkecil dan memiliki kesamaan dan membentuk populasi. Sehingga algoritma genetika tidak cocok dalam penjadwalan jeda iklan pada Most FM.

\section{KESIMPULAN}

Dari hasil penelitian yang dilakukan maka penulis dapat menyimpulkan bahwa algoritma genetika tidak dapat diterapkan dalam penjadwalan iklan radio di Most FM di karenakan algoritma genetika pada dasarnya terbentuk dari partikel terkecil dan memiliki kesamaan yang membentuk populasi lalu terjadi kromosom. Sehingga algoritma genetika tidak cocok dalam penjadwalan jeda iklan. Proses penjadwalan jeda iklan tersebut tidak selalu mendapatkan hasil yang optimal di karenakan algoritma genetika sangat di pengaruhi oleh fungsi acak. Aplikasi Microsoft Visual Studio.net 2008 yang dirancang dapat mengoptimalkan penjadwalan jeda iklan yang ada.

\section{REFERENCES}

[1] Nasri, Kecerdasan Buatan, Yogyakarta: Graha Ilmu, 2014

[2] Muliadi, Pemodelan algoritma genetika pada sistem penjadwalan perkuliahan prodi ilmu komputer universitas lambungmangkurut banjarmasin, 2014.

[3] I Gusti Ayu Desi Saryanti, I Kadek Wijanegara, Penerapan metode algoritma genetika untuk penjdwalan mengajar.bali, 2017

[4] Farah, B.P. (2014). Penerapan Algoritma Genetik untuk Vehicle Routing Problem with Time Windows (VRPTW) Pada Kasus Optimasi Distribusi Beras Bersubsidi. Universitas Brawijaya, Malang.

[5] Atih, Ani. 2011. Periklanan dan Etika: Pengontrolan Terhadap Iklan dan Penilaian Etis Terhadap Iklan .com/2014/05/periklanan dan etika-pengontrolan.html. Diakses Hari Rabu, 14 Mei 2014.

[6] Eka Iswandy, 2014, Perancangan sistem informasi tentang pencatatan hasil tes kemampuan fisik atlet (studi kasus : Fakultas Ilmu Keolahragaan (UNP) Padang.

[7] Rosa A.S, M. Shalahuddin. 2011. Modul Pembelajaran Rekayasa Perangkat Lunak (Terstruktur dan Berorientasi Objek). Modula. Bandung.

[8] Ade Hendini, (2016), Pemodelan UML sistem informasi monitoring penjualan dan stok barang, Pontianak.

[9] Hidayatullah, P. 2012. Visual Basic .NET. Informatika Bandung. Bandung

[10] Aditya, Primananda Arif. Dasar -Dasar Pemrograman Database Dekstop Dengan Visual Basic.NET 2008. Jakarta. Elex Media Komputindo. 2013

[11] Arief M Rudianto, (2011). Pemrograman Web Dinamis menggunakan PHP dan MySQL.C.V ANDI OFFSET.Yogyakarta. 